\title{
Angola - território e identidade. Crónicas de Luís Fernando
}

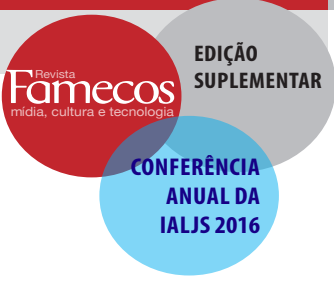

\section{Angola - territory and identity. Chronicles by Luís Fernando}

\begin{abstract}
Alice Donat Trindade
Professora Associada ao Instituto Superior de Ciências Sociais e Políticas (ISCSP) da Universidade de Lisboa, pesquisadora do Centro de Administração e Políticas Públicas (CAPP). Tem publicado nas áreas de Estudos Americanos, Jornalismo Literário e ensino de línguas para fins específicos. Ela é membro fundador da Associação Internacional de Estudos de Jornalismo Literário (IALJS), da qual foi presidente entre 2010 e 2012.

<atrindade@iscsp.ulisboa.pt>
\end{abstract}

\section{RESUMO}

O jornalismo literário é um género com história para os contadores de estórias reais. Este artigo analisa em um corpus, crónicas do jornalista angolano Luís Fernando originalmente publicadas no magazine Vida, as formas de abordagem de elementos primordiais de formação de identidade, os conceitos de território e língua portuguesa, procurando ainda estabelecer os pontos de contacto desses artigos com o género para o qual propomos inclusão, o jornalismo literário. Os estudos sobre jornalismo angolano são ainda escassos, por razões académicas, mas também por motivos relacionados com a história e situação política do país, emergido em 2002 de cinco décadas de guerras. A análise crítica do discurso permite entrever o processo de reaproximação cultural gradual ao território angolano promovido pelas crónicas junto da população, após o distanciamento causado pela apropriação territorial bélica anterior, bem como o questionamento de alguns aspectos da língua portuguesa.

Palavras-chave: Jornalismo literário. Angola. Crónica.

\begin{abstract}
Literary journalism is, by now, a genre with a history for the story-tellers of the real. This article analyses the corpus chosen, journalist Luís Fernando's chronicles, originally published by Angolan magazine Vida, seeking the types of approach used to grasp seminal elements in identity formation, the concepts of language and territory, also aiming to locate the elements present in the articles that allow its inclusion in literary journalism. Studies in Angolan journalism are scarce, both due to academic reasons and to motives found in the historical and political situations of the country, which emerged in 2002 from five decades of wars. Critical discourse analysis of texts has allowed glimpsing efforts toward a gradual, cultural reconnection to Angolan territory promoted by these chronicles, aiming at the whole population, after a long period of estrangement caused by its former military appropriation, as well as questioning of some aspects of the Portuguese language.
\end{abstract}

Keywords: Literary Journalism. Angola. Chronicle.

\section{Introdução}

O Jornalismo literário é um género jornalístico desenvolvido em diferentes países com as suas cambiantes culturais próprias, reportando, contudo, sempre sobre acontecimentos e factos observáveis, manifestando um impulso para reclamar o real (Keeble, 2012). O editor deste volume, que contém contribuições de académicos de diversos países e tradições jornalísticas, refere: "A sua escrita está radicada em observação/testemunho/representação disciplinada de 
pessoas 'reais' inseridas em narrativas provenientes de acontecimentos 'reais' que serão, em princípio, apesar de não o terem que ser na prática, verificáveis" (Keeble, 2012, p. 7; tradução nossa'). Todo o jornalismo deve reportar com acuidade fatos deste tipo, reais, verificáveis: variáveis desta tarefa de reportar, cultural e linguisticamente influenciadas, surgem em diferentes latitudes, onde mostram distintas, mas também semelhantes, pessoas reais envolvidas em acontecimentos reais.

O jornalismo literário utiliza técnicas de escrita literária: joga com ponto de vista, diálogo, detalhe e construção de cena, como apontava Tom Wolfe na sua obra The New Journalism (Wolfe, 1973). Adiciona-se ainda a capacidade imaginativa, como referido pela autora em escrito anterior: "O papel desempenhado pela imaginação, e que consiste na selecção de elementos pré-existentes e da sua apresentação em formas nunca vistas, tem sido um elemento essencial na construção de identidade e de Nação" (Trindade, 2012, p. 292; tradução nossa²) Esta capacidade imaginativa permite a organização ou reorganização de temas, a tomada de factos, indivíduos, acontecimentos que passariam despercebidos ou que passam a ser abordados de forma a conferirIhes importância acrescida ou significado diferente daquele que lhes é atribuído na visão formatada pela experiência rotineira do quotidiano. Nas circunstâncias especiais de construções identitárias, em especial quando relacionadas com a construção fatual e conceptual de Nação, a capacidade do jornalismo literário de confrontar o público com reflexão, interpretação e criação de quadros conceptuais relacionados com um país em gestação ou formação é relevante, como foi mostrado, por exemplo, no caso de Cabo Verde e dos escritos de Pedro Cardoso, abordados em obra anteriormente referida (Trindade, 2012).

Acresce, em obra editada por Richard Keeble em 2014, um outro aspeto relacionado com a identificação autoral ao jornalismo literário. Refere-se em um dos capítulos que a jornalista brasileira Eliane Brum, não reconhece ela própria que pratica o género, mas, apenas, nas palavras da autora, "bom jornalismo" (Dominguez, 2014, p. 241). Ou seja: o jornalismo literário aborda temas que estarão menos presentes na agenda mediática e é, por vezes, praticado por jornalistas que não se atribuem adesão a esse tipo de género jornalístico.

Esta ausência de identificação com o género prende-se, eventualmente, com tradições mais ou menos estabelecidas de estudo deste tipo de jornalismo

1 No original: "Imagination in this role of selecting existing elements and presenting them in forms never before devised has been an essential element in identity and nation building".

2 No original: "Raj Kamal Jha of the Indian Express and Sudarshan Thakur of Tehelka, who did their bit to encourage young people to write 'stories' rather than 'reports'[...]". 
em algumas geografias. Nos Estados Unidos, por exemplo, o já referido Tom Wolfe publicou em 1973 um verdadeiro livro de estilo do New Journalism, designação adoptada nessa década para o jornalismo literário na colectânea de textos com o mesmo título, lançando as fundações teóricas para a atualização do género na segunda metade do século XX nesse país. Estes estudos seriam retomados nas décadas seguintes por académicos seminais no estudo de jornalismo literário comoThomas B. Connery (1992), Norman Sims (1984), ou John C. Hartsock (2000). Mas, já no século XIX, Matthew Arnold anunciava um New Journalism, ainda que acusando-o de ser 'feather-brained': "Temos experienciado a observação de um novo tipo de jornalismo inventado por um indivíduo enérgico e esperto" (Arnold, 2016; tradução nossa ${ }^{3}$ ). Arnold, aparentemente, analisava W. T Stead a propósito do artigo 'Maiden Tribute', em que Stead criticava a exploração infantil de crianças na Inglaterra vitoriana (Campbell, 2003, p. 20): assuntos incómodos, como o da exploração infantil, viam-se assim admitidos à categoria de merecedores de atenção jornalística, ainda que suscitassem, neste caso, comentários depreciativos por parte de um consagrado intelectual da época, Matthew Arnold.

António Hohlfeldt escrevia em 2009 que a história do jornalismo, e outros estudos que versassem esta forma de escrita, ainda estavam para ser escritos nos países africanos (Hohlfeldt, 2009, p. 137). Refira-se que, no caso específico da história do jornalismo angolano em língua portuguesa, tinha sido publicado em 1964 por Júlio Castro Lopo o volume Jornalismo de Angola: Subsídios para a sua História (1964), que reporta sobre as três diferentes fases, encontradas pelo autor na história jornalística do território (Lopo, 1964, p. 19) que, por essa altura, pouco excedia um século de longevidade. Durante o período estudado, a maior parte das publicações era dada à estampa em Luanda, mas Castro Lopo enumera ainda as publicações sediadas por todo o país: Moçâmedes, Novo Redondo, Benguela, Malange, Dalatando, Sá da Bandeira (Lubango), Silva Porto (Bié), Santo António do Zaire, Lobito, Nova Lisboa (Huambo) e ainda da Missão Católica do Bailundo.

Como se poderá aplicar neste panorama de pesquisa académica ainda incipiente, proporcionado pelos muitos obstáculos e recomeços do jornalismo em Angola, uma leitura e análise de artigos publicados em meio tão distante, em diversos aspectos, daquele que se regista no eixo do Atlântico, entre a Europa e as Américas? Esta é uma questão a que se tem vindo a responder

3 No original: "We can say what it is in particular that discourse brings into the complex relations which constitute social life: meaning and making meaning". 
com estudos pioneiros como os que se debruçam sobre formas de jornalismo literário existentes em países onde, até há poucos anos, este género não se revelava, nem pesquisava a sua existência, podendo dar como exemplo a Índia. No capítulo "Indian literary journalism in the age of the mobile phone", Nalini Rajan reproduz as orientações dadas a jornalistas no início do século XXI: "Raj Kamal Jha do Indian Express e Sudarshan Thakur de Tehelka encarregaramse de encorajar profissionais jovens para escreverem 'estórias' em vez de reportagens" (Rajan, 2014, p. 263; tradução nossa ${ }^{4}$ ). Curiosamente, estes editores reproduzem o conselho que, no início da carreira do jornalista literário americano de origem judia, Abraham Cahan, Ihe foi transmitido por colegas do jornal nova-iorquino, The New York Sun, com o qual colaborava, citando Charles Dana, o editor e proprietário da publicação. Dana tinha dito, uns anos antes, a estudantes da Columbia College: "O que é importante é que ele [um bom jornalista] tenha olhos para ver e senso para compreender o que vê "(Stein, 1969, p. 357; tradução nossa ${ }^{5}$. Ou seja: em momentos diferentes, em locais diversos, surge uma quase imperiosidade jornalística de verificar, muito atentamente, quais são as estórias que acompanham e fazem as vidas das pessoas. No caso dos artigos de Luís Fernando, iremos apontar algumas das origens e inspiração na direção de Cuba, país localizado numa América Latina especialmente vibrante na sua própria forma deste jornalismo, a crónica.

Jornalismo literário, new journalism ou jornalismo de outras designações mas idêntico pendor, utilizam pesquisa acurada, diálogo dos intervenientes nas estórias, cuidado nos detalhes e não limitam os temas, dedicando atenção a todos, mesmo os que podem causar incómodo. Implicam atenção aguda a esses temas, mesmo que sejam menos comuns, ou menos refletidos pelo público em geral. Dedica ainda cuidado à forma, importando, em muitas circunstâncias, técnicas e estratégias literárias como fidelidade ao discurso original dos intervenientes, construção do texto através da apresentação de cenas que promovem o avanço da estória através da lente e da escrita do seu autor.

O jornalismo literário não tem, contudo, receita única para todas as línguas em todo o mundo. Qualquer escrita reflecte cultura própria e o jornalismo literário não é exceção. Existem temas universais: pobreza (como relatado pelo inglês W. T. Stead há dois séculos, ou contemporaneamente por Eliane Brum); mudanças sociais como as relatadas pelo norte-americano Wolfe na colecção

4 No original: "Raj Kamal Jha of the Indian Express and Sudarshan Thakur of Tehelka, who did their bit to encourage young people to write 'stories' rather than 'reports'[...]".

5 No original: "What is important is that he [a good newspaperman] has eyes to see and sense to understand what he sees". 
The New Journalism nos anos de 1970; ou estórias de formação de identidade nacional, como as do cabo-verdiano Pedro Cardoso, no início do século XX. No tempo e no espaço viaja este género de jornalismo.

\section{Breve nota metodológica}

Em matéria de método, o corpus será abordado utilizando análise crítica do discurso na concetualização operacionalizada por Norman Fairclough. Escreve o autor: "Podemos referir o que é trazido, em particular, para as complexas relações que constituem a vida social pelo discurso: significado e elaboração de significado "(Fairclough, 2013, p. 3; tradução nossa'). Refere ainda Fairclough a dificuldade de formulação do conceito de discurso, enquanto conceito autónomo, isolado de outros como, por exemplo, o de "poder". Ou seja, este autor propõe a análise crítica de discurso, enquanto relacionamento entre discurso e outro objeto, acrescentando ainda a questão do género do próprio discurso. No caso presente, o referido objeto a ter em conta será o território e o género a referenciar será um de escrita jornalística, o de jornalismo literário em português.

Fairclough propõe que um discurso é constituído pelo relacionamento entre acontecimentos de comunicação concretos - refere o exemplo de artigos jornalísticos - e entidades mais abstratas, como línguas ou géneros (Fairclough, 2013 , p. 3). Na sequência do quadro teórico traçado por este autor, o presente artigo pretende localizar no corpus escolhido, constituído por crónicas, aqui tomadas como passíveis de inclusão no género jornalismo literário, os sinais existentes da relevância da evolução do conceito de território (angolano), para o autor e para os seus leitores, enquanto pedra angular de (re)construção identitária, suportada pela língua portuguesa. A análise compreenderá o levantamento da escolha vocabular na área semântica "território", mas também as associações feitas entre os elementos lexicais utilizados, e a sua relevância para a construção do quotidiano dos 'heróis' das estórias ou para o próprio autor, enquanto intervenientes nas mesmas, e as consequências para as identidades dos envolvidos, enquanto cidadãos angolanos. Todo o processo decorre no âmbito de um outro tipo de discurso, a atualização da língua portuguesa, no contexto angolano do século XXI.

6 No original: "We can say what it is in particular that discourse brings into the complex relations which constitute social life: meaning and making meaning". 


\section{O País - Angola}

Angola é um país da costa ocidental de África, cujo território principal é limitado a norte e a nordeste pela República Democrática do Congo, a leste pela Zâmbia, a sul pela Namíbia e a oeste pelo Oceano Atlântico, com um território de 1. 246. $700 \mathrm{Km}^{2}$, independente desde 1975. O censo de 2014 aponta como resultados preliminares para a população que o habita o número de 24,3 milhões de habitantes, dos quais 6, 5 milhões em Luanda, o que constitui $27 \%$ da população total. Temos perante nós um grande território habitado por um número relativamente baixo de cidadãos angolanos, disperso em grande parte do território e concentrado na capital. Segundo Jean Gottmann (1975), território é um conceito gerado por pessoas, que organizam espaço com o intento de auxiliar os seus objetivos. Ora, o território a que se convencionou chamar Angola foi utilizado pelos seus habitantes, deacordo com descobertas arqueológicas, nos primeiros séculos da nossa era, para acolher regimes pastoralistas a acrescentar aos anteriores, de caçadores recoletores (Parkington, 2000), ou seja, território ocupado e utilizado por diversos grupos, interligado por razões de natureza histórica e de relacionamento político entre agregados autóctones africanos, ainda não angolanos. A chegada de europeus causou desenvolvimentos para $o$ território africano, que modificaram o curso dos eventos da forma abrupta que sucede aquando de contactos entre povos com histórias e características muito diferentes, frequentemente conducentes a conflito. Os períodos de descoberta, exploração e colonialismo prévios às duas guerras mundiais traçaram um curso para os, entretanto delineados, territórios/países africanos que desembocou em movimentos de autodeterminação e lutas independentistas.

A partirdosanos de 1960, ainda em período colonial português, a economia e indústrias de exportação dependiam de três matérias-primas essenciais: diamantes, ferro e petróleo. Esta exploração ainda se mantém em territórios localizados um pouco por todo o território, desde Cabinda, o enclave territorial na República do Congo (Congo-Brazzaville) situado a norte, mas também no Huíla (centro), Lunda (Nordeste). Agricultura e pecuária foram profundamente afetadas pelo longo período de guerra, inicialmente colonial (1961-1974) e, ulteriormente, civil (até 2002). A migração de população para as cidades, especialmente para Luanda, em busca de maior segurança, acompanhadas pelas consequências de muitos anos de guerra, como a proliferação de minas e a lenta desminagem de terrenos por todo o país, ainda não concluída, levaram ao abandono progressivo de territórios e da sua atividade económica. Lembrese, contudo, a ligação estreita entre identidade nacional e território enunciada por Guntram Herb: “A identidade nacional está identicamente dependente do 
território pois apenas o território providencia prova tangível da existência da nação e das suas raízes históricas" (Herb, 1999, p. 10; tradução nossa7).

Entra assim Angola no século XXI, com a assinatura dos acordos que formalizam o fim da guerra civil. Assiste-se ao crescimento do PIB, ao desenvolvimento das indústrias extrativas e aos consequentes aumentos de volume de exportação. Simultaneamente, a sociedade civil reorganiza aspectos de uma sociedade em tempo de paz, como os órgãos de comunicação social escrita. Neste contexto, surge em 2008 o jornal O País, inicialmente semanário e atualmente diário, com versão online e um magazine semanal Vida, neste momento com a publicação suspensa. As publicações pertencem a um grupo de media privado, Medianova, que detém ainda outros órgãos de comunicação social como a Rádio Mais, a TV Zimbo e uma revista económica, Exame.

\section{Trajetos do jornalismo literário em Angola - As Vidas de Luís Fernando}

Diversos jornalistas que escrevem no jornal O País contribuíam ainda para o magazine Vida. Neste magazine escrevia, por exemplo, Luís Fernando, e outros jornalistas, como Magdala Azulay, Reginaldo Silva ou José Kaliengu, que se detinham em artigos que se aproximam do conceito de jornalismo literário que pretendemos estudar, cruzando-se nalguns deles as questões específicas de território e identidade.

Luís Fernando (LF) nasce em 1961 em zona rural, perto do Uíge, e começa a actividade como jornalista bem cedo. É bolseiro para estudar jornalismo em Cuba e desenvolve ao longo da sua carreira atividade em diferentes meios de comunicação em Angola. Foi premiado com a maior distinção para jornalistas angolanos, o Prémio Maboque de Jornalismo, em 2011, com a coleção de artigos escritos até então para o jornal O País. Numa entrevista disponível online que se seguiu à entrega do prémio, LF referiu ao entrevistador, Pitigrili:

Quando escreve as suas reportagens sente que está a amputar possíveis romances? Claramente. Mas como sei que nunca hei-de dispor de tempo suficiente para dar forma de romance a centenas de roteiros maravilhosos que descubro pelo jornalismo, não invento nem tento ter mais olhos que barriga, aceito a situação, resigno-me (Pitigrili, 2011).

7 No original: "National identity is similarly dependent on territory because only territory provides tangible evidence of the nation's existence and its historical roots". 
Estes 'roteiros maravilhosos' têm relevo no historial deste género jornalístico em exemplos que se podem encontrar em autores como a mais recente Nobel da Literatura, Svetlana Alexeivich, que escreve sobre as questões levantadas no território ucraniano de Chernobyl, ou sobre os soviéticos em "O Homem Soviético - Um tempo de desencanto", publicado em 2016 em Portugal. John Hartsock (2011) refere a tradição russa/soviética nesta área, designada de reportagem (literária), um género nascido ainda no século XIX com sketches, esboços de personagens e eventos, e que prossegue, desde então, com escritos mais ou menos polémicos, conformados politicamente, ou não, ao regime dominante. Da tradição do Leste europeu resultam essas duas formas similares ao jornalismo literário: apontamentos jornalísticos breves, herdeiros da tradição do século XIX de atribuição de dignidade de publicação a estórias ou personagens menos frequentes nas agendas mediáticas, ou as obras mais longas, fruto de pesquisa aturada, como as de Alexeivich.

Luís Fernando fez como referido, estudos universitários em Cuba: quando frequentava a universidade, e como ele próprio revela no artigo "Tempos de WWW. CARAS\&FACTOS. CO. MZ": "Nos meus anos de bolseiro em Cuba (1986 a 1992), um dos meus maiores prazeres eram as leituras ao domingo, no jornal Juventud Rebelde, das crónicas de Enrique Nuñes Rodríguez e Gabriel García Márquez" (Fernando, 2015g, p. 66). Considerando a história da crónica ou do 'testimonio' na América Latina de fala hispânica, Fernando invoca a tradição antisistema de Garcia Marquez e os artigos de Nuñes Rodriguez, autor, guionista e jornalista sancionado pelo regime cubano. O jornal Juventud Rebelde, ainda em publicação, é o órgão de comunicação social do regime cubano dedicado à juventude. Claramente, as influências dos dois autores sul-americanos mantiveram-se até ao presente, levando à escrita de artigos 'testemunho', sobre personagens 'menores' e reflexões relativamente curtas sobre a realidade do quotidiano angolano. Recorde-se, a propósito, o artigo de Pablo Calvi, onde este académico de origem argentina chama a atenção para o desenvolvimento das formas de jornalismo próximas ao jornalismo literário na América Latina, como o testimonio:

Institucionalizada e legitimada porgovernos progressivose socialistas, e especialmente pela revolução cubana, a literatura testemunhal latino americana tem consolidado, particularmente entre o final dos anos de 1950 e o início dos anos de 1980, os seus objectivos políticos, e não poderá ser analisada sob critérios meramente artísticos. Fazê- 
lo, equivaleria a não reconhecer o locus cultural que ela ocupa na experiência latino americana (Calvi, 2010, p. 77; tradução nossa ${ }^{8}$ ).

LF teve assim contacto próximo com autores que estavam inseridos nesta corrente latino-americana, tanto em termos estilísticos, como de origem temática. LF reporta, a este propósito e em diversas entrevistas, caraterísticas comuns que se podem rever na sua escrita. Refere, por exemplo, em entrevista em 16 de Outubro de 2015 a Venceslau Mateus da agência ANGOP:

\begin{abstract}
Angop - Quais são as suas principais fontes de inspiração? LF: Gosto muito do passado, daquilo que vivenciei, das estórias que ouvi ao longo da vida ou do que me contam no presente. Tenho alma de contador de estórias e sinto-me dotado de uma sensibilidade aguda para escutar e captar experiências que depois recrio, amplio, ficciono. Bebo muito do mundo que palpita ao meu redor. Sou uma mente inquieta e tudo o que sacode a modorra, a mesmice, entusiasma-me. As crónicas semanais que escrevo há sete anos são uma demonstração disso (Mateus, 2015).
\end{abstract}

\title{
As crónicas: a reconquista do território angolano
}

Os textos a analisar foram publicados no magazine Vida entre 2010 e 2016, sendo que os publicados entre Novembro de 2010 e Novembro de 2011 foram compilados no volume intitulado Três Anos de Vida (2014). As crónicas semanais referidas por Fernando na entrevista acima referida confirmam a vontade do autor de 'sacudir a modorra' e de procurar, com a sua sensibilidade, os detalhes distintivos da vida angolana contemporânea, os componentes materiais e imateriais de uma cultura e identidade em (re)formulação constantes.

As estórias do passado e presente como fontes de inspiração estão bem patentes nos textos em estudo. Comecemos por tomar alguns que referem a cidade de Luanda.

O primeiro, "Luanda e as suas voltas misteriosas I", publicado a 29 de Janeiro de 2016, refere os problemas recorrentes da higiene da cidade capital de

8 No original: "Institutionalized and legitimized by progressive and socialist governments, and especially by the Cuban Revolution, Latin American testimonial literature has consolidated, especially since the late 1950s and until the early 1980s, its political finality, and could not be analyzed in solely artistic terms. To do so would fail to acknowledge the cultural place it occupies in the Latin American experience". 
Angola, foco de muitos artigos, local de residência de um quarto da população do país:

\begin{abstract}
Nas minhas deambulações por Luanda antiga, teve graça o tropeçar infinitas vezes com o elemento do ADN da cidade que mais se mostra resistente, roçando os muros do imutável: o conflito cíclico com a higiene pública. [...] O lixo e a sujeira permanentes são adversidades que, por exemplo, num certo momento do século XIX esteve à beira de enlouquecer a cidade com uma onda de histeria que não poupou ninguém (Fernando, 2016, p. 68).
\end{abstract}

No início deste artigo, o autor refere Luanda como "nossa casa comum" epíteto empregue por um grupo de responsáveis da cidade. Fernando apelida ainda a sua cidade de "urbe quatricentenária", "o lugar nascido sob o nome de São Paulo de Assunção de Loanda", possuidora, já no século XIX, de território que se estende desde a "linha do mar, desde o Bungo à praia do peixe". Ou seja, a cidade de Luanda é antiga, tem história conhecida e registada desde há séculos, neste caso para lembrar que os problemas de higiene pública já deixavam os luandenses do século XIX deveras enervados, e em busca de soluções para os recém-chegados que, já então, acorriam à cidade. Luanda tem assim história de local de acolhimento de quem procura melhor destino.

Em "A quase morte do Tio Manzambi", a acção ocorre há mais de trinta anos e deparamo-nos com uma descrição da Luanda dos anos de 1980: "Numa cidade então feliz com a fluidez do trânsito, deu para dar várias voltas ao casco urbano, da Ilha à Samba, do aeroporto à FTU, da Cuca ao porto..." (Fernando, 2014, p. 77). Apelida o autor a cidade de feliz, invocando a faceta positiva de tempos de escassez, devidamente evocados numa estória, que tem como personagem principal Eduardo Mankenda, então jovem comerciante expedito. Os seus ardis permitiam obter licenças para fornecimentos de bens, com justificação de necessidade de provisões para circunstâncias de família, nomeadamente para o 'funeral' de um tio que, a quando de visita a Luanda, encontra em casa do sobrinho a requisição de víveres para as suas próprias cerimónias fúnebres. A tradição e respeito pelos mais velhos foram assim atropelados pelo sobrinho comerciante astuto, mas que termina a história com um enxovalho administrado pelo mais velho.

Luanda era nos anos de 1980 cidade pouco movimentada, justamente a penar pelas faltas causadas pela guerra em curso. Fernando lembra esses tempos, pois no momento de escrita: "Me incomoda profundamente a maneira 
como hoje adultos e menos adultos nos lançamos, qual hienas esfomeadas, sobre a mesa a transbordar em mesas opulentas onde poucos ou ninguém pensa sequer na miséria à volta" (Fernando, 2014, p. 76). De cidade de escassez, passou-se à Luanda de opulência escassa, disponível apenas para os que se sentam às mesas fartas. Mas a crónica termina com um regresso a costumes enraizados exigidos pela gravidade da falta: "O tio esbofeteou-o com toda a autoridade e raiva permitidas pela ligação aos ancestrais e, no dia seguinte, estavam os dois na pequena aldeia de Maquela do Zombo a exorcizar com banhos, mixórdias e unguentos Eduardo Makenda" (Fernando, 2014, p. 78). 0 espaço da cidade cedeu ao espaço da aldeia de origem, onde se regressa aos ritmos de vida mais sinceros e onde as tradições são devidamente respeitadas, sem recurso a artifícios.

Outros tempos mais recentes mantêm tradições antigas: prosseguindo nos hábitos alimentares, é-nos apresentada numa crónica a época das mangas, quando as zungueiras (vendedoras ambulantes) se encarregam de animar o espaço urbano com a mercadoria da época: "Na cidade, os mercados, as pracetas, os largos, as esquinas, mas sobretudo as ruas em movimento, enchemse de mangas" (Fernando, 2014, p. 15). A fartura dos frutos da terra enche a cidade de imagens conhecidas, que enche a família do autor de um acordo sem contestação: "Todos aceitam que a fruta de que lhes conto histórias associadas de infância, quase sempre risíveis e traquinas, entre naturalmente para o seio da família" (Fernando, 2014, p. 16). Mas a venda dos frutos abundantes, mas perecíveis, não se faz sem riscos para as zungueiras empreendedoras:

As vendedoras de maior audácia [...] deixam ficar uns quantos montículos de mangas, à confiança. Regra geral entendem-se com outras mulheres que trabalham para as famílias e que depois se encarregam de comunicar aos 'chefes' que há mil, dois mil ou quatro mil kwanzas por pagar à zungueira Carol ou Rita (Fernando, 2014, p. 17).

O circuito comercial informal, baseado em confiança entre as mulheres que vendem e as mulheres que trabalham nas casas de família, revela a vivência de uma cidade imensa, mas onde se reproduzem, nestes detalhes, os preceitos herdados de tradições comerciais próprias, de comércio informal mas que garante a subsistência de muitas famílias, dependentes dos proventos da venda ambulante. 
E por último, a presença de macacos na cidade, animais esperados em zonas menos urbanas, mas não na cidade de Luanda:

\begin{abstract}
Na cidade acossada por mil e uma maleitas - chuvas, charcos, poças, lodo, lama, escuridão, lixo, mosquitos, malária, ladrões, assaltantes, assassinos, marginais de faca em punho, burladores, prostitutas, proxenetas, traficantes etc. etc. etc... - a raiva entendeu se alistar e elevar os níveis de angústia. Os habitantes não acharam qualquer piada aos passeios diários dos símios. Protestaram. Gritaram (Fernando, 2015c, p. 50).
\end{abstract}

À onda dos macacos, Luís Fernando acrescenta, como justificação para mais esta revolta, todas as outras pragas que pululam na cidade, sejam humanas ou de outro tipo, todas elas causadas, de forma mais ou menos direta, pelos homens, mesmo as que aparentemente são de origem natural, como os fenómenos meteorológicos.

Quando o espaço territorial se associa ao tempo - meteorológico verifica o leitor as notas de diferença e proximidade, onde se partilham questões comuns, pois parte das caraterísticas de um território são as que se ligam ao clima local:

\begin{abstract}
Não faz muito, veio visitar-nos o meu cunhado André Alfredo "Fefé" que se decidiu mudar para o desértico Namibe e os relatos que deixou sobre a incidência do frio obrigou logo meia tribo a refazer a agenda. Se ele estava para receber a visita dos de Luanda, por dever de reciprocidade, no decurso do presente Cacimbo, vai ter a santa paciência de aguardar que chegue Novembro, Dezembro ou até Janeiro, quando tudo se faz tórrido e os mais optimistas acreditam que podem fritar ovos no deserto (Fernando, 2015d, p. 50).
\end{abstract}

Como no relacionamento regrado revelado na crónica "A quase morte do Tio Manzambi", o dever de reciprocidade de visita de elementos familiares, é aqui tratado com a devida delicadeza, mas sempre com humor. O Namibe desértico e frio não permite viagens ao autor e família que, em outro texto, "Cacimbo Glorioso" exaltava a beleza do Sol dessa época do ano, quando o contemplava nas férias em casa da Avó Zola, em Canjenje: "sol carregado de meiguice, generoso, aparentemente até mais lento na sua busca de outros mundos para iluminar" (Fernando, 2014, p. 90). Esta questão do tempo do cacimbo é algo que, a não vir acompanhado de memórias de infância, não 
prenuncia nada de positivo para o autor, que não se inibe de se anunciar como 'friorento'. Ainda assim, o tempo é agora assunto de interesse mediático e do público, com atenção às notícias de temperaturas baixas, especialmente as do Lubango, "Está na moda espreitar o Lubango, que se vem repetindo no exagero da descida do mercúrio dos termómetros com os seus zero grau de mínima quase dia sim, dia não" (Fernando, 2014, p. 90).

O país de grandes dimensões que é Angola sofreu uma redução de disponibilidade territorial para a sua população durante as décadas de guerra civil, vendo-se agora na situação de reencontrar e utilizar a grandeza, indisponível até há bem pouco tempo. Ao regime colonial e às sucessivas organizações de território a que se assistiu, a guerras com inimigos externos ou entre grupos nacionais, segue-se a reconquista pacífica do território pelo cidadão, dependente do empoderamento desse mesmo cidadão.

Ponto provado pela senhora idosa, que se regozija pela reabertura da linha férrea e do tráfego de comboios entre o Lobito e Luau, atravessando o território angolano desde a costa até às fronteiras com a Zâmbia e República Democrática do Congo:

Uma anciã dos tempos das velhas locomotivas, antes portanto da cruel suspensão em consequência da guerra, declarava-se livre, feliz, com direito a morrer realizada [...], porque testemunhava [...] ter os seus filhos e netos a verem o comboio pela primeira vez (Fernando, 2015b, p. 66).

A inauguração oficial contou com a presença do Presidente da República, referida no texto, mas Fernando opta por escolher, para assinalar o fato, 'o momento sublime' da senhora que se regozija entre o povo.

Povo de cidadãos, como a "Domingas Serrote, a zungueira das tarefas", título da crónica que descreve uma das milhares de vendedoras ambulantes de Luanda:

Foram várias colegas que também escrevem a poesia da sobrevivência no asfalto, à Baixa de Luanda, a darem-me a dica em uníssono: - Esta senhora da foto? Sim, conhecemos, é a Domingas das tarefas. Vende ali, naquele pilar (Fernando, 2015f, p. 50). 
Domingas, zungueira, vendedora ambulante, vende os seus produtos sempre perto de um determinado pilar no Bairro dos Coqueiros em Luanda, reconhecido como 'seu' pelas colegas de profissão. Aproveita o tempo não empregue na venda para aprender a ler e escrever, a competência que lhe faz falta para a vida e o trabalho, o que lhe valeu a alcunha de zungueira das tarefas (trabalhos de casa a realizar pelos alunos da escola). "Aquele pilar" é dela, é o seu território, aquele onde até uma equipa da televisão pública portuguesa, RTP, a foi filmar'. A mulher trabalhadora que não teve oportunidade de estudar, quando criança, traça para si o seu próprio programa de formação, levado a cabo apesar de todas as dificuldades da vida e da confusão de papéis que gera para si própria. É adulta, é estudante, é zungueira "de tarefas" e tem uma identidade suficientemente elástica para abarcar todos esses papéis.

Ademais, os desencontros entre identidade cívica e identidade étnica, descritas, por Guntram Herb (1999), como sendo, a primeira ligada ao território do estado, e a segunda baseada em língua e cultura comuns, encontram-se de forma muito visível, na dificuldade de Luís Fernando em escrever acerca de realidades menos conhecidas, dos territórios "menores", das zonas agrícolas, porque lhe faltam as palavras em português para esse efeito: "Na verdade, que nome têm em português as três pedras que servem de base às panelas - ou tachos se preferirem - nas cozinhas a lenha nas aldeias africanas" (Fernando, 2015e, p. 66).

A questão da língua é aqui abordada, uma questão que em países como Angola não é de menor importância, pois são muitas as línguas locais e o português não é suficiente, ainda que enriquecido localmente, para traduzir toda a realidade e pensamentos africanos. A língua constitui-se como questão identitária de relevo, pois o repositório lexical permite a verbalização (ou impede-a, neste caso).

Regressando à vastidão territorial, retornemos à reposição do trajecto maior de comboio:

Quando o conflito armado recrudesceu no pós-Independência, não foi preciso ser entendido em assuntos de guerra para qualquer cidadão intuir que o longo caminho sobre carris que ia do Lobito ao Luau seria, com toda a certeza, uma das primeiras vítimas. Não havia condições, nas circunstâncias específicas da nossa desavença bélica, para uma defesa consistente de um traçado com mais de mil

9 Vídeo clip sobre a história obtido em 6 de Setembro de 2015 e acedido em 5 de Julho de 2016. Disponível em: <http://www. rtp. pt/noticias/mundo/zungueiras-querem-aprender-a-ler v856484> 
quilómetros estendido por vales, planícies, pontes, florestas, chanas (Fernando, 2015b, p. 66).

O território tinha deixado de ser civil: passou a conceito de aproveitamento militar, destruindo-se por essa razão as ligações ferroviárias que permitiam a travessia de Angola de oeste a leste. Durante anos, não foi possível percorrer o extenso percurso, semidestruído pela actividade bélica. Mas, em 2015, foi finalmente reposto o movimento ferroviário:

\begin{abstract}
A utilíssima e estratégica infra-estrutura estava, inerte como gigante moribundo, à mercê da inconsciência selvagem de todas as guerras. Todos os que amam Angola, a sentem profundamente e vibram com as suas conquistas, emocionámo-nos quando vimos o comboio fazer a sua entrada triunfal na vila, mais de trinta anos depois. De um só golpe, o Luau reganhou o seu velho orgulho de porta do progresso e se transformou em nó de convergência e fortuna para três nações, Angola, RDC e Zâmbia (Fernando, 2015b, p. 66).
\end{abstract}

O território, a identidade, a língua: como os três pés que sustentam as panelas dos cozinhados das aldeias africanas, também estes três componentes se encontram nas crónicas de Fernando, exemplos de jornalismo literário angolano, onde autor e as suas estórias e personagens se encontram de forma democrática, deixando espaço a todos para fazerem ouvir a sua voz.

\title{
Discussão da Análise
}

Os artigos de Luís Fernando confrontam-nos com um tipo de escrita e de conteúdos que, dentro do género jornalismo literário, se abeira da crónica, na sua versão latino-americana com longa tradição que remonta ao século XIX. Pablo Calvi define-a, dessa maneira, exemplificada por jornalistas distintos, como José Marti: “Uma forma de artigo breve, até 2.000 palavras, sob tópicos diversos, destinada a estar revestida de aspectos de cor, entretenimento e informação e - na maior parte das vezes - profundamente política" (Calvi, 2012, p. 305; tradução nossa ${ }^{10}$ ).

10 No original: "A form of brief article of no more than 2, 000 words on different topics, meant to be both colorful, entertaining, informative and - more often than not- extremely political". 
Muitas destas características podem ser encontradas nos escritos de Fernando, talvez pela influência experienciada por este jornalista, e já anteriormente referida, do seu período de formação universitária em Cuba. 0 próprio José Martí era cubano, e a sua escrita foi tomada por diversos autores como seminal no século XIX para questões da identidade, de busca do que era o americano latino, o americano escrito em espanhol ou português, "the search for lo americano" (Martinez-Echazabal, 1998, p. 21). Pode atentar-se, a este respeito, o que José Martí escreveu em missiva dirigida ao Ministro de Negócios Estrangeiros da Guatemala em 11 de abril de 1877:"O meu ofício, meu querido amigo, é cantar todo o belo, incentivar o entusiasmo pelo que é nobre, admirar e provocar admiração pelo grande. Escrevo todos os dias, sobre o que vejo em cada dia" (Martí, 2016, p. 16; tradução nossa'11). Esta carta faz parte do volume editado Nuestra America, colectânea de diversos textos de Martí, em que este autor tenta definir o que é 'o americano', por aquilo que vê e observa, abandonando modelo europeu. Luís Fernando pretende, nos seus artigos, mostrar os seus conterrâneos, as suas características e pertenças, o que significa ter uma identidade angolana, por oposição a outras e em consonância com o que os cidadãos deste país vão construindo para se definir, mostrar o que é 'o angolano'. Mostrar, desfamiliarizando, pois o que é óbvio, visto todos os dias e entendido como 'natural' não tem, forçosamente que ser assim.

O discurso alternativo do jornalismo literário permite esse olhar reflexivo, que Phyllis Frus referia da seguinte forma: "Se os mídia não estão criando uma 'realidade' nova, eles devem estar re-estruturando a forma como a experimentamos, ao afectarem a forma como nos apercebemos do mundo" (Frus, 1994, p. xv; tradução nossa ${ }^{12}$ ).

No excerto da entrevista e nos textos de Luís Fernando podemos captar indícios de uma das questões fulcrais desta comunicação, o relacionamento entre identidade e território. Já foi referido o conceito de território adotado território enquanto conceito gerado por pessoas, adaptando-o ao sucesso dos seus objectivos. Ora, os objetivos a atingir na sociedade angolana, portadora de constructo identitário-territorial originado, na sua versão histórica moderna, nos primórdios da presença europeia, serviriam, a partir do século XVI, os objetivos de um planeamento europeu para o território e habitantes africanos. Os habitantes das zonas que viriam a constituir Angola ficaram adstritos a uma identidade humana limitada pela prática da escravatura, e que misturava e

11 No original: "Mi oficio, cariñoso amigo mio, es cantar todo lo bello, encender el entusiasmo por todo lo noble, admirar y hacer admirar todo lo grande. Escribo cada día sobre lo que cada día veo".

12 No original: "If mass media are not creating a new 'reality', they may be restructuring the way we experience it, by affecting the way we perceive the world". 
confundia diferentes etnias numa definição que não considerava quaisquer diferenças efetivamente existentes, como refere o autor Guntram Herb:

Desta forma, criaram-se dois tipos de identidade: uma identidade cívica (também identificada como 'nação cívica' ou 'política'), focada e congruente com o território do estado, e uma nação étnica, que enfatiza a comunidade de língua e cultura e procura unir todos os seus membros em território contíguo (Herb, 1999, p. 12; tradução nossa $\left.{ }^{13}\right)$.

O país, que se tornou independente em 1975, tinha reunido num território diversas nações étnicas, com territórios próprios em alguns casos, bem como línguas próprias. A identidade cívica, ligada ao novo país, liga-se a um território que ainda vai sofrer convulsões ligadas a interesses internos e externos, com estabilização em tempo de paz apenas no início do século XXI. A construção identitária decorre assimem oposição a variados modelos e perdendo, em virtude das migrações internas e externas das populações, características ancestrais, como ligação a línguas africanas, a costumes fundados nas localizações de onde os migrantes eram provenientes.

No corpus analisado neste artigo encontramos referência a alguns locais de Angola, localizados em zonas conhecidas do autor, por serem da sua origem familiar - residência atual ou anterior, ou residência de familiares - (artigos $A$ cidade e os macacos, ou 2015 e o cacimbo), mas também de acontecimentos nacionais e de tomada de território por outros compatriotas (artigos Domingas Serrote, a zungueira de tarefas, ou Volto já, vou ao Leste de comboio). No mapa poderá ver-se mais claramente a sua distribuição pelo território angolano:

13 No original: "Thus, two different types of identities came into existence: a civic identity (also identified as a 'political' or 'civic nation'), which was focused on and mostly congruous with the territory of the state, and an ethnic nation, which stressed the commonality of language and culture and sought to unite all members in a contiguous territory". 
- Mapa 1 - Local referidos nos textos do corpus

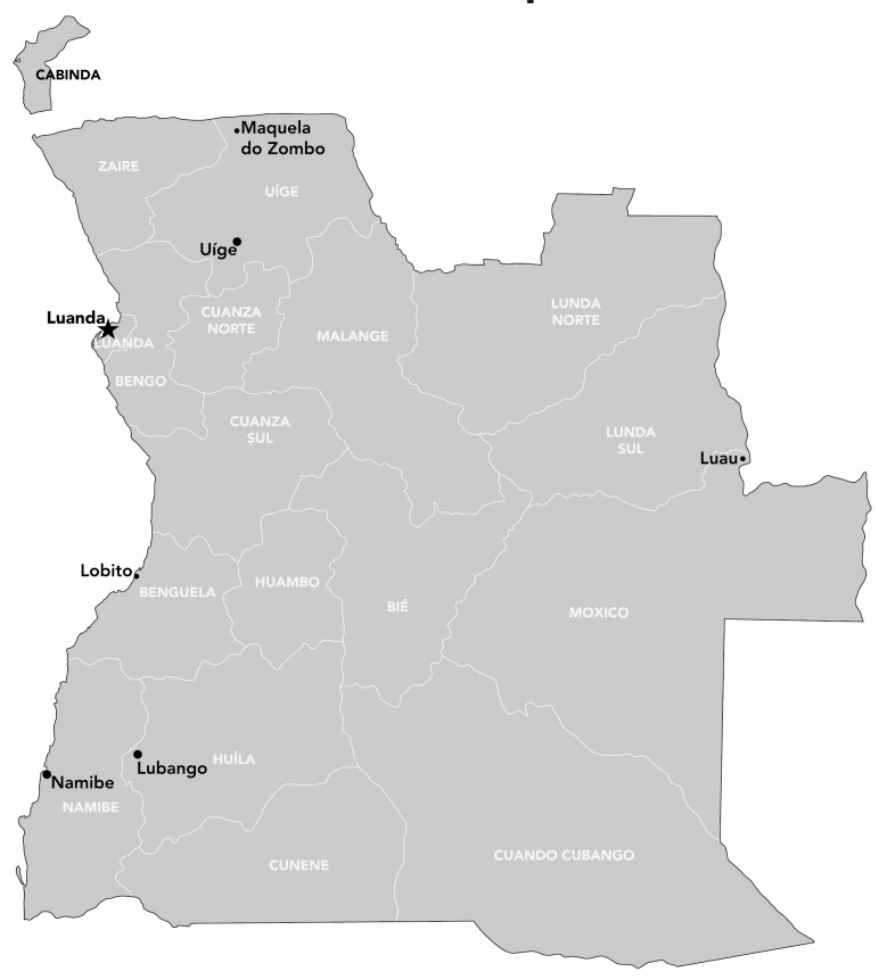

Fonte: Gabinete de Comunicação e Imagem ISCSP

Este artigo aborda apenas uma parte das crónicas de Luís Fernando. Tendo a publicação das mesmas iniciada em 2008 e sido mantida, sem interrupção e semanalmente, desde então, o corpo de obra publicada do autor constitui um manancial de mais olhares sobre os objetos de análise deste artigo, os constituintes do discurso e da sua articulação com outros conceitos, de acordo com o modelo inspirado por Fairclough. O mapa acima poderá vir a ser preenchido de muitas outras localizações e ligações.

E assim chega o nosso autor, Luís Fernando aos tempos atuais, com as características políticas, sociais e identitárias resultantes dos acontecimentos históricos. Como David Abrahamson refere no capítulo The Counter Coriolis Effect da obra Literary Journalism across the Globe, onde relaciona os desenvolvimentos do género jornalismo literário dos anos finais do século $\mathrm{XX}$, com o efeito físico no movimento de objectos em queda, consoante estão no hemisfério Norte (com rotação para a direita) e hemisfério Sul (com rotação para a esquerda): "O resultado é um género jornalismo literário no Sul que é bastante autocrítico, em parte devido a uma visão mais sombria da natureza humana" (Abrahamson, 
2011, p. 82, tradução nossa ${ }^{14}$ ). David Abrahamson manifesta neste capítulo a opinião que, enquanto no hemisfério norte o jornalismo literário tende a ser mais reformista e contra-corrente (e contra o efeito Coriolis), no Sul ele manifesta menos discordância com regimes vigentes e tolerância com status quo. Será esse o caso do autor em apreço?

Luís Fernando tem estado ligado, profissionalmente, a meios de comunicação estatal e privados ao longo da sua carreira. A atividade regular enquanto jornalista e correspondente permitiu um conhecimento profundo da realidade angolana, dentro do contexto social e político das últimas décadas: de domínio colonial, a estado independente, com convulsões internas e finalmente em estado pacificado mas com as dificuldades inerentes a muitos países que sofrem de questões decorrentes do que se convencionou chamar "doença holandesa", ou seja, que a abundância de uma matéria prima como petróleo possa causar inacção nas áreas agrícola ou industrial (Karl, 1997, p. 5).

Luís Fernando escreve sobre o que vê, e também procura o que é angolano, assim pretendendo registar por escrito o que constitui a identidade dos cidadãos deste país. Refere o território, que é próximo, como o ocupado pela zungueira luandense, ou o distante, reconquistado através da recuperação da linha de caminho-de-ferro, que une a costa ao interior do país; refere a língua portuguesa, quando ela chega, ou não é suficiente para retratar a realidade. Preocupa-se com o essencial e, tal como no artigo que relata a reabertura do caminho-de-ferro trans-angolano, dá a palavra ao povo, reconhecendo a presença das figuras de estado e das hierarquias, mas nunca esquecendo que $o$ quotidiano é feito pelas pessoas comuns, que podem sofrer por decisões menos avisadas das hierarquias, mas que permanecem como a memória e identidade do povo.

\section{Considerações Finais}

Território algo reconquistado em termos de disponibilidade de utilização para atividade económica individual e informal, para discussão da sua qualidade sanitária, para vivência familiar repartida em diferentes pontos, para transporte ferroviário, faltará ainda muito em termos de consolidação da ligação território/ identidade angolana para o século XXI. Os tempos não estão fáceis no ano de 2016 para os angolanos: as questões económicas internas e externas estão menos favoráveis do que no ano de início do jornal $O$ País. Mas os textos de um autor como Luís Fernando permitem, tanto a angolanos como a estrangeiros,

14 No original: "The result is a genre of literary journalism in the South that is quite self-critical, driven in part by a bleaker vision of human nature". 
conhecer as narrativas e os discursos dos pequenos heróis do quotidiano, as vendedoras ambulantes, os migrantes, os viajantes do recém-redescoberto território.

A composição destas histórias em textos jornalísticos cumpre as condições de detalhe, ponto de vista, estilo de jornalismo literário tal como é concebido no hemisfério norte, acrescido de temática e estética africana próprias, reveladas na escolha de temas e palavras, na valorização do autóctone, na leveza de uma escrita que reflete uma realidade dura, com poucos direitos adquiridos, pouco conforto, mas muita vivacidade na escrita, tal como a das vidas que retrata. Não será o jornalismo literário da tradição do leste europeu de reportagem; não será o jornalismo literário dos EUA, na senda de Wolfe ou de Joseph Mitchell. Aproximase talvez mais da tradição da crónica latino-americana, por admissão do próprio autor e por similitudes de escrita, temática e uso de linguagem. É jornalismo literário angolano, segue algumas das regras do género mas transforma-as, não por oposição a outros modelos, mas por descoberta de caminhos próprios, enformados pelos atores envolvidos: o jornalista que escreve e o meio social e humano que retrata.

É o jornalismo literário do contador de estórias, como diz este autor de si próprio, o repositório das notícias que não são suscetíveis de causar perturbação política, mas que consolidam e reconhecem a existência dos menos poderosos, o que em Angola, como em qualquer lugar do mundo, é de relevo bastante.

\section{REFERÊNCIAS}

ABRAHAMSON, David. The Counter Coriolis Effect. In: BAK, John (Ed.). Literary Journalism Across the Globe: journalistic traditions and transnational influences. Amherst and Boston: University of Massachusets Press, p. 79-84, 2011.

ARNOLD, Matthew. Up to Easter. In: ARNOLD, Matthew. The Nineteenth Century No. CXXIII, p. 629-643, mai. 1887. Disponível em: <http://www. attackingthedevil. co. uk/related/easter.php>. Acesso em: 27 jun. 2016.

CALVI, Pablo. Latin America's own “New Journalism”. Literary Journalism Studies, v. 2, n. 2, p. 63-86, Fall 2010.

. José Marti and the Chronicles that Created Modern Latin America. In: KEEBLE, Richard L.; TULLOCH, John. Global Literary Journalism. Exploring the Journalistic Imagination. New York: Peter Lang, p. 299-316, 2012.

CAMPBELL, Kate. W. E. Gladstone, W. T. Stead, Matthew Arnold and a New Journalism: Cultural Politics in the 1880s. In: Victorian Periodicals Review, v. 36, n. 1, p. 20- 
40, Spring 2003.

CONNERY, Tomas. A Sourcebook of American Literary Journalism. Representative Writers in an Emerging Genre. New York: Greenwood Press, 1992.

DOMINGUEZ, Juan. New Journalism in Portuguese. In KEEBLE, Richard; TULLOCH, John. Global Literary Journalism. Exploring the Journalistic Imagination. Volume 2. New York: Peter Lang, v. 2, p. 235-246, 2014.

FAIRCLOUGH, Norman. Critical Discourse Analysis: The Critical Study of Language. Oxon: Routledge, 2013.

FERNANDO, Luís. Três Anos de Vida. Luanda: Mayamba, 2014. . Um Intruso com Atitude. Vida, p. 66, 23 jan. $2015 a$. . Volto já, vou ao Leste de comboio. Vida, p. 66, 20 fev. 2015b. . A cidade e os macacos. Vida, p. 50, 8 maio 2015c. 2015 e o cacimbo. Vida, p. 50, 19 jun. 2015d.

. Tão familiares e tão desconhecidas - II. Vida, p. 66, 7 ago. 2015e. Domingas Serrote, a zungueira das tarefas. Vida, p. 50, 11 set. $2015 f$. . Tempos de www. caras\&factos. co. mz. Vida. p. 66, 4 dez. 2015 g. . Luanda e as suas voltas misteriosas I. Vida, p. 68, 29 jan. 2016.

FRUS, Phyllis. The Politics and Poetics of Journalistic Narrative. The Timely and the Timeless. Cambridge: Cambridge University Press, 1994.

GOTTMANN, Jean. The evolution of the concept of territory. In: Social Science Information, Paris, v. 14, n. 3, p. 29-47, ago. 1975.

HARTSOCK, John. Literary Reportage. The "Other" Literary Journalism. In BAK, John (Ed. ). In: Literary Journalism across the Globe: Journalistic Traditions and Transnational Influences. Amherst and Boston: University of Massachusetts Press, p. 23-46, 2011.

HARTSOCK, John. A History of American Literary Journalism. The Emergence of a Modern Narrative Form. Amherst: University of Massachusetts Press, 2000.

HERB, Guntram. National Identity and Territory. In: Nested Identities. Nationalism, Territory and Scale. Lanham, Maryland: Rowmann and Littlefield Publishers Inc., p. 9-30, 1999.

HOHLFELDT, Antônio. Imprensa das colônias de expressão portuguesa: primeira 
aproximação. Comunicação \& Sociedade, v. 30, n. 51, p. 135-154, jan./jun. 2009. <http://dx.doi.org/10.15603/2175-7755/cs.v30n51p135-154>.

KARL, Terry. The Paradox of Plenty: Oil Booms and Petro-States. Berkeley: University of California Press, 1997.

KEEBLE, Richard; TULLOCH, John. Global Literary Journalism. Exploring the journalistic imagination. New York: Peter Lang, v. 1, 2012.

LOPO, Júlio. Jornalismo de Angola. Subsídios para a sua história. Luanda: Centro de Informação e Turismo de Angola, 1964.

MARTÍ, José. Nuestra America. Barcelona: Red Ediciones SL, 2016.

MARTINEZ-ECHAZABAL, Lourdes. Mestizaje and the Discourse of National/Cultural Identity in Latin America, 1845-1959. Latin American Perspectives, v. 25, n. 3, p. 21-42, mai. 1998. Disponível em: <http://www.jstor.org/stable/2634165>. Acesso em: 18 jul. 2016.

MATEUS, Venceslau. Luís Fernando a favor da leitura de autores angolanos nas escolas. Angop. Agência Angola Press, 17 dez. 2015. Disponível em: <http:// www. portalangop. co. ao/angola/pt_pt/noticias/entrevistas/2015/9/42/LuisFernando-favor-leitura-autores-angolanos-nas-escolas, 2baabd11-5d57-46988ff2-cf37c27bc988. html>. Acesso em: 16 out. 2015.

PARKINGTON, J. E. Southern Africa: hunters and food gatherers. In MOKHTAR, G. General History of Africa II: The Ancient Civilizations of Africa. Paris: UNESCO Publishing, 2000, p. 639-670. Disponível em: <http://unesdoc. unesco. org/ images/0018/001842/184265eo.pdf >. Acesso em: 18 jul. 2016.

PITIGRILI, Luís Fernando. Pitigrili: Angola, Luanda, política mundial, sociedade, automobilismo, ralis, e tudo o mais.... Luanda, 13 set. 2011. Disponível em: <http://angola-luanda-pitigrili.com/who\%E2\%80\%99s-who///luis-fernando>. Acesso em: 18 jul. 2016.

RAJAN, Nalini. Indian literary journalism in the age of mobile phones. In KEEBLE, Richard; TULLOCH, John. Global Literary Journalism. Exploring the Jounalistic Imagination. New York: Peter Lang, v. 2, p. 261-276, 2014.

SIMS, Norman. The Literary Journalists. New York: Ballantine Books, 1984.

STEIN, Leo. The Education of Abraham Cahan. Philadelphia: The Jewish Publication Society of America, 1969.

TRINDADE, Alice Donat. Lush Words in the Drought: The Literary Journalism of Pedro Cardoso. In: KEEBLE, Richard; TULLOCH, John. Global Literary Journalism. Exploring the journalistic imagination. New York: Peter Lang, v. 1, p. 287-298, 2012. 
WOLFE, Tom. The New Journalism. New York: Harper \& Row Publishers, 1973.

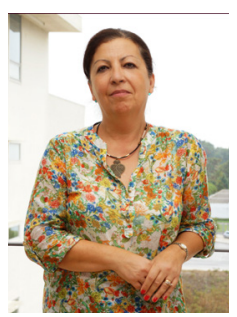

Recebido em: 20.7. 2016

Aceito em: 26. 7. 2016

Endereço do autor:

Alice Donat Trindade <atrindade@iscsp.ulisboa.pt>

Instituto Superior de Ciências Sociais e Políticas - Universidade de Lisboa

Rua Almerindo Lessa, $\mathrm{s} / \mathrm{n}^{\circ}$

1300-663 - Lisboa - Portugal 